\title{
Examples of extremely low-frequency magnetic fields in a Finnish metro station
}

\author{
L. Korpinen ${ }^{1 \star}$, A. Lähdetie ${ }^{2}, \AA$ A. Amundin ${ }^{3}$, H. Piippo ${ }^{4}$ and L. Sydänheimo ${ }^{1}$ \\ 1 Tampere University of Technology, ELT, 33101 Tampere, Finland. \\ 2 Helsinki City Transport, 00099, Helsinki, Finland. \\ 3 Combinova AB, 19740 Bro, Sweden. \\ ${ }^{4}$ Rejlers Oy, 45100 Kouvola, Finland.
}

Received 3 August 2014 - Accepted 23 April 2015

\begin{abstract}
The aim of this pilot study was to present examples of extremely low-frequency (ELF) magnetic fields in a Finnish metro station. The metro trains are powered by $750 \mathrm{~V}$ DC voltage supplied through a conductor rail next to the running rails. We measured magnetic fields with a magnetic field meter MFM 3000 in 17 cases when a train was leaving the platform in the same metro station. The maximum measured magnetic field was $5400 \mathrm{nT}$ (at $1 \mathrm{~m}$ height and $4.3 \mathrm{~m}$ from the conductor rail). The magnetic field stayed at this level for a very short time after the metro left the platform. It is possible that there are also DC magnetic fields near the metro as the train leaves the station because the trains are powered by DC voltage. Therefore, it is also important to measure DC fields and DC currents in the future.
\end{abstract}

Keywords: magnetic field / metro / exposure

\section{Introduction}

The Helsinki metro system includes two metro lines, which serve 17 metro stations; the length of the network is $21.1 \mathrm{~km}$. The number of passengers was 62.2 million in 2012, and will be more when the 14-km-long Western Metro Extension opens in 2016. HKL Metro Transport has 54 carriage pairs (42 M100-series trains made by Valmet (Finland) and 12 M200-series trains made by Bombardier Transportation (Germany)). Together, the M100-series trains and the M200series trains traveled 14.6 million pair of carriages $\times$ kilometers (HKL Metro Transport, 2012).

According to the standard IEC/TS 62597, in railways, three electromagnetic sources can affect human beings: rolling stock, traction power supply and signaling equipment (IEC, 2011). According to the standard EN 50500, the detectable emission of these three sources is in the frequency range from DC up to $20 \mathrm{kHz}$ (CENELEC, 2008). In Helsinki, the metro trains are powered by $750 \mathrm{~V}$ DC voltage supplied through a conductor rail next to the running rails. Returning current is conducted through the running rails (Vanhatalo, 2010). The current rail system implemented in the power supply system can cause magnetic interference.

The electric system of the Finnish metro is different from many other magnetic field (MF) sources in Finland, e.g., power lines or substations. The aim of this paper was therefore to measure the MF in a metro station and to present examples

\footnotetext{
^ leena.korpinen@tut.fi
}

of extremely low-frequency (ELF) magnetic fields. The measurements performed in this pilot study focus on the dynamic condition, e.g., during a train departure.

\section{Measurement situations and methods}

The standard EN 50500 (CENELEC, 2008) describes the required conditions for measurements of a magnetic field on rolling stock in dynamic conditions. These conditions are met when i) the rolling stock starts from a standstill with maximum acceleration to maximum speed, ii) the traction circuits are under voltage and operating, iii) the auxiliary circuits are operating, and iv) all the appliances such as air conditioning/heating, lights, electric generators, window heater, etc. are active.

The measurements were performed at Kamppi underground metro station in two measurement places: A and B. Place A was on the area where the front of the train stopped and Place B was on the area behind where the train stopped. Figure 1 shows (a) an example of the metro train at Kamppi metro station, (b) the MFM 3000 in measurement location A, and (c) the meter in measurement location B.

We studied M100-series trains (height $3.7 \mathrm{~m}$, width $3.2 \mathrm{~m}$ and length $44.2 \mathrm{~m}$ ) and M200-series trains (height $3.7 \mathrm{~m}$, width $3.2 \mathrm{~m}$ and length $44.3 \mathrm{~m}$ ). Both trains are powered by $750 \mathrm{~V} \mathrm{DC}$ voltages, and the maximum speed of the trains in passenger traffic is $80 \mathrm{~km} \mathrm{~h}^{-1}$. The distance from the device for measurement to the conductor rail was $4.3 \mathrm{~m}$. We used 


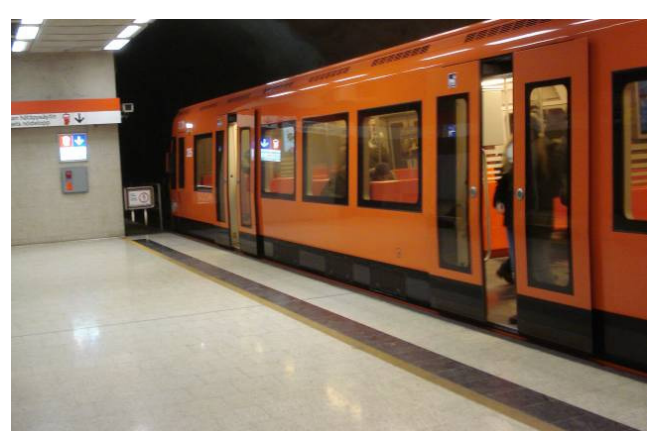

(a)

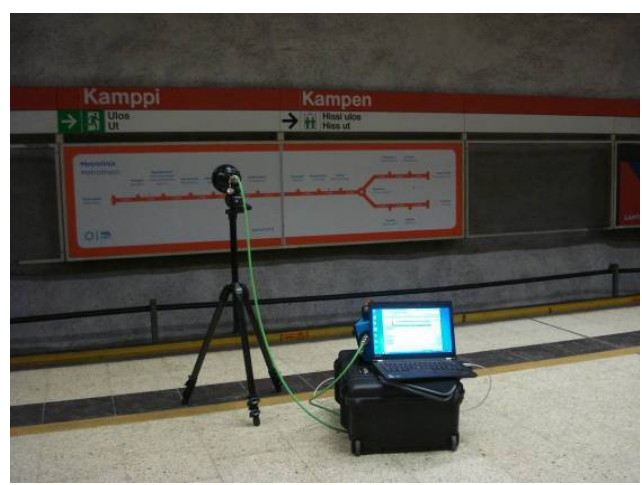

(b)

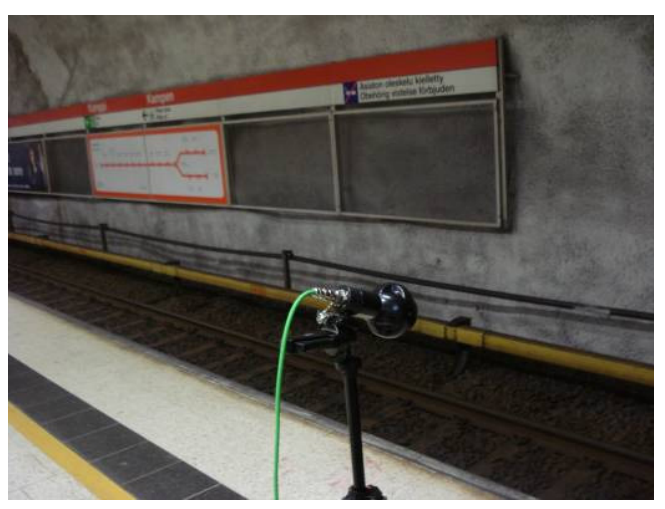

(c)

Figure 1. (a) Example of metro train, (b) MF meter in measurement place A and (c) MF meter in measurement place B.

a magnetic field meter MFM 3000 supplied by Combinova $\mathrm{AB}$ that contained a separate probe. The frequency range was $5 \mathrm{~Hz}-400 \mathrm{kHz}$. The dynamic range of the meter was from $10 \mathrm{nT}$ to $10 \mathrm{mT}$ with true RMS measurements. We also utilized a laptop with the MFM 3000 meter and a tripod. The measurement height was $1 \mathrm{~m}$.

We measured magnetic fields (MFs) on 17 separate occasions as a train was leaving the metro station. We conducted all of the measurements in the same metro station. In area A, we took measurements for 14 train departures, and in place B for three train departures. We did not select particular trains; we tried to take measurements for all departing trains. The temperature was $13.2^{\circ} \mathrm{C}$, and relative humidity was $35 \%$.
Table 1. Maximum values of ELF magnetic fields as trains left the station.

\begin{tabular}{lcc}
\hline No. of train & Place & Magnetic field, nT \\
\hline 1 & A & 522 \\
2 & A & 1472 \\
3 & A & 3823 \\
4 & A & 798 \\
5 & A & 5400 \\
6 & A & 3500 \\
7 & A & 1212 \\
8 & A & 1949 \\
\hline & A & 1383 \\
10 & A & 1039 \\
11 & A & 1124 \\
12 & A & 1177 \\
13 & A & 2224 \\
14 & A & 3585 \\
15 & B & 4122 \\
16 & B & 1824 \\
17 & B & $1405^{*}$ \\
\hline
\end{tabular}

*Probe in different position.

Table 2. Example MF values (RMS), as a train (no. 15) was leaving the metro station.

\begin{tabular}{ccc}
\hline $\mathbf{n}$ & Time (hh:mm:ss) & Magnetic fields $\mathbf{( 5} \mathbf{~ H z}-\mathbf{4 0 0} \mathbf{~} \mathbf{H z}), \mathbf{n T}$ \\
\hline 1 & $11: 40: 15$ & 329.61 \\
2 & $11: 40: 25$ & 276.41 \\
3 & $11: 40: 30$ & 291.92 \\
4 & $11: 40: 40$ & 828.93 \\
5 & $11: 40: 45$ & 4122.76 \\
6 & $11: 40: 55$ & 506.66 \\
7 & $11: 41: 05$ & 470.71 \\
8 & $11: 41: 10$ & 427.97 \\
9 & $11: 41: 20$ & 380.58 \\
\hline
\end{tabular}

\section{Results}

\subsection{Background fields}

The background magnetic field, when the train was not at the metro station, varied from $80 \mathrm{nT}$ to $296 \mathrm{nT}$. The duration of the background field measurements was a few minutes.

\subsection{Magnetic fields when the train left the metro station}

Table 1 provides the maximum values of the ELF magnetic fields as a train left the station. The maximum value varied from $522 \mathrm{nT}$ to $5400 \mathrm{nT}$; the average $\pm \mathrm{SD}$ was $2151 \mathrm{nT} \pm$ $1361 \mathrm{nT}$. Table 2 gives an example of MF values (RMS) as the train no. 15 was leaving the metro station. The first measurement was performed at 11:40:15 am, when the train started to move, and lasted until 11:41:20 am. Figure 2 shows magnetic fields at different frequencies at 11:40:40 am for the same train.

We also measured the $\mathrm{x}-, \mathrm{y}$ - and $\mathrm{z}$ - components of the MF at Place B. The $\mathrm{z}$-component was in the direction of the yellow 


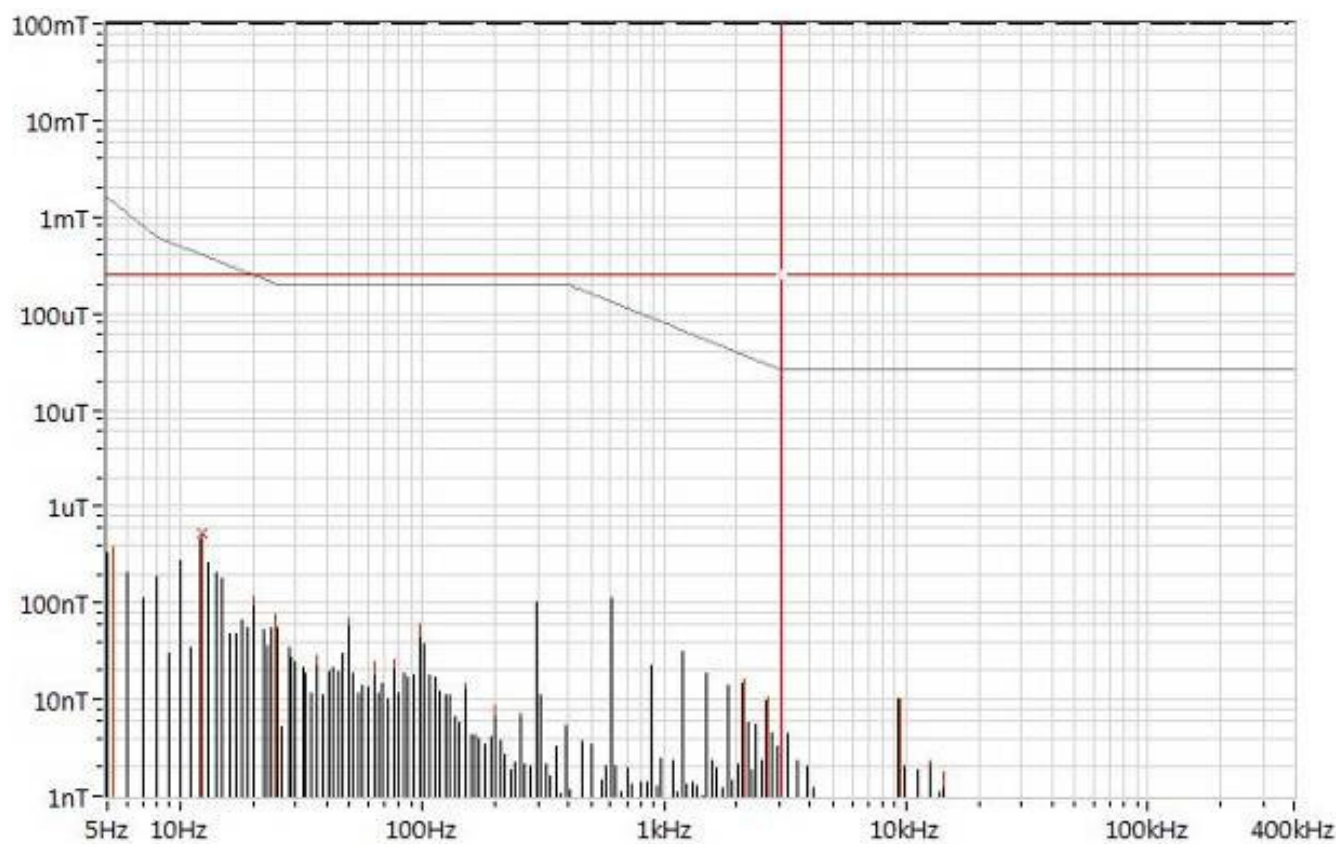

Figure 2. Magnetic fields at different frequencies at time 11:40:40, train no.15.

conductor rail. The $\mathrm{x}$-component was in the horizontal direction, and the y-component was in the vertical direction. The highest magnetic fields were in the z-component with a maximum value of $4069.7 \mathrm{nT}$, when the train left. At the same time, the x-component was $389.72 \mathrm{nT}$, and the $\mathrm{y}$-component was $531.91 \mathrm{nT}$.

\section{Discussion}

This paper presents only example measurements of exposure to ELF magnetic fields on a metro station in Finland. Measurements were performed in one metro station at two different places. Based on this pilot study, we noted that the measured values are low, with the highest value being $5400 \mathrm{nT}(5.4 \mu \mathrm{T})$. In addition, the field was at this maximum level for a very short time. Table 2 reveals that the field was between $329.6 \mathrm{nT}$ and $380.58 \mathrm{nT}$ for about one minute. Thus, the exposure period is quite short. Passengers who use the metro are not typically standing on the platform near the train as it leaves the metro station. Passengers who are arriving at the metro station are, for example, coming down the escalator as the train leaves.

We measured the frequency range $5 \mathrm{~Hz}-400 \mathrm{kHz}$, and the reference values are different based on which frequency we use in the analysis. For example, for $25 \mathrm{~Hz}-400 \mathrm{~Hz}$, the reference value is $200 \mu \mathrm{T}$; thus, the ELF MF near the metro trains is quite low (maximum value 5.4 $\mu \mathrm{T}$ ) (ICNIRP, 2010).

Our hypothesis was that the highest component of the magnetic field is the one that was in the direction of the yellow conductor rail. We can accept this hypothesis because the $\mathrm{z}$-component of the magnetic field was higher than the other components in our measurements. However, these measurement data can only be seen as a guide, because we did not measure $\mathrm{x}-$, y- and z- components in all our measurements. These data were reported previously for one example (train no. 15) in our conference paper (see Table 2; Korpinen et al., 2014).

Different magnetic field sources of extremely lowfrequency fields have been reported in metros (WHO, 2007). For example, in the driver's cab of the London underground, the AC magnetic flux density extends up to $20 \mu \mathrm{T}$ (frequency $100 \mathrm{~Hz}$ ), and in a passenger car of a suburban train (at table height), the AC magnetic flux densities were 16-64 $\mu \mathrm{T}$ (frequency $100 \mathrm{~Hz}$ ) (Allen et al., 1994; Chadwick and Lowes, 1998). Hämäläinen et al. (1999) measured magnetic field exposure ranging in frequency from $10 \mathrm{~Hz}$ to $2 \mathrm{kHz}$ in electrified trains in Finland. The average levels were 0.3-290 $\mu \mathrm{T}$ for passengers and 10-6000 $\mu \mathrm{T}$ for workers (Hämäläinen et al., 1999). In our measurements, the highest value (5400 nT) was lower than the results in the earlier studies. However, we measured the magnetic fields only on the metro station, not inside the metro train.

In the future, it is important to measure DC fields as well because DC magnetic fields can occur near DC currents. The current measurements are also important because the waveform of the current and the MF are similar.

\section{Conclusion}

In our study, we measured the magnetic field as metro trains started moving and left the underground Kamppi metro station. The highest magnetic field detected was $5400 \mathrm{nT}$ $(5.4 \mu \mathrm{T})$. However, the influence of the train lasted only about one minute. Therefore, the public exposure to magnetic fields caused by metro trains is quite low at metro stations. However, we took measurements only at one metro station and did not measure DC fields, which can also occur near metro trains. Therefore, there are still areas to be investigated. In the future, it is also important to measure DC magnetic fields. 


\section{References}

Allen S.G., Blackwell R.P., Chadwick P.J. (1994) Review of occupational exposure to optical radiation and electric and magnetic fields with regard to the proposed CEC physical agents directive. Chilton, National Radiation Protection Board (NRPB-R265).

CENELEC (2008) EN 50500 Measurement procedures of magnetic field levels generated by electronic and electrical apparatus in the railway environment with respect to human exposure.

Chadwick P., Lowes F. (1998) Magnetic fields on British trains, Ann. Occup. Hyg. 42 (5), 331-335.

Hämäläinen A.M., Hietanen M., Juuti P., Juutilainen J. (1999) Exposure to magnetic fields at work and public areas in the Finnish railways. In: Proceedings of the Second World Congress for Electricity and Magnetism in Medicine and Biology, Bologna, pp. 785-787.

HKL (2012) Annual report, http://www.hel.fi/hki/hkl/en/ About+HKL/Annual+Reports (Accessed 16 Feb 2014).
IEC 62597 (2011) Measurement procedures of magnetic field levels generated by electronic and electrical apparatus in the railway environment with respect to human exposure.

International Commission on Non-ionizing Radiation Protection (2010) Guidelines for limiting exposure to time-varying electric and magnetic fields $(1 \mathrm{~Hz}-100 \mathrm{kHz})$, Health Phys. 99 (6), 818-836.

Korpinen L., Lähdetie A., Amundin Å., Piippo H., Sydänheimo L. (2014) Example measurements of exposure to ELF magnetic fields on the metro station in Finland. In: 8th International Workshop on Biological Effects of Electromagnetic Fields, 21-25 September 2014, Varna.

Vanhatalo E. (2010) The possibilities to reuse regenerative braking in the Helsinki Metro System. Master's Thesis. Aalto University of Science and Technology (in Finnish).

World Health Organization (2007) The Extremely low frequency fields. Environmental Health Criteria Monograph no. 328.

Cite this article as: L. Korpinen, A. Lähdetie, A. Amundin, H. Piippo, L. Sydänheimo. Examples of extremely low-frequency magnetic fields in a Finnish metro station. Radioprotection 50(3), 229-232 (2015). 